\title{
Study on Cracking of Steel Lined Reinforced Concrete Penstock Based on Continuous - Discontinuous Method
}

\author{
Hailin WU', a , Liangcai Zhu ${ }^{2, b}$, Fubing Cui ${ }^{3, ~ c}$, Zhiqiang Zheng ${ }^{4, d}$ \\ College of Hydraulic \& Environmental Engineering, Three Gorges University, Yichang 443002, \\ China

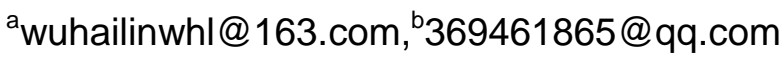

\begin{abstract}
Key words: steel lined reinforced concrete penstock; bearing capacity; extended finite element methed; crack width

Abstract: The numerical simulation of steel lined reinforced concrete penstock model of a hydropower station is carried out by continuous-discontinuous numerical method (extended finite element method). This paper focuses on the numerical calculation method of the crack process and the crack width of the concrete pipe, and compared with the model test results. The results show that the cracking process of pipe outsourcing concrete simulated and the steel stress distribution are close to the model test results by the extended finite element method. The fractured width obtained by the numerical method is in good agreement with the experimental data.
\end{abstract}

\section{Introduction}

The crack problem of steel lined reinforced concrete penstock is one of the focus of engineering[1,2]. Generally speaking, the steel lined reinforced concrete penstock can be regarded as a continuum before cracking, and it is a discontinuous body after the macroscopic fracture. At present, numerical methods, such as finite element method[3] and discrete element method[4,5], which are used to calculate the structure of steel lined reinforced concrete penstock are difficult to simulate the process of simulating the transition of concrete from continuum to discontinuous body. Based on the extended finite element method[6,7], this paper studies the continuous - discontinuous numerical simulation method which can fully reflect the process of concrete fracture initiation. Combined with a large-scale indoor model test of steel lined reinforced concrete penstock of a hydropower station, simulated penstock outsourcing of concrete from the cracks generated to carry through the whole process, and based on the finite element method, the numerical calculation method for the width of concrete cracks is proposed. Compared with the model test results, the cracking process of the concrete and the stress distribution of the steel are analyzed, the width value of the concrete crack in the concrete pipe is obtained by the numerical calculation method, it can provides a new effective way for the cracking analysis of the steel lining reinforced concrete pressure pipe.

\section{The Principle of Extended Finite Element Method}

Based on the unit decomposition, the extended finite element method is used to improve the displacement function of the conventional finite element method. There are two functions added in the general finite element displacement function. One is the asymptotic function that reflects the crack tip singularity, the other is the jump function that reflects discontinuity of the crack surface, which makes the discontinuous characteristic be described. At the same time, the extended finite element is used to locate the fracture and track the growth of the crack. 
The Basic Theory of Extended Finite Element. The extended finite element extension of the displacement function consists of three parts, namely, the general finite element part, the crack through part and the crack tip part. After the extended degree of freedom, the distribution of the node is shown in Fig. 1. The specific expression of the displacement function is as follows:

$$
U=\sum_{\mathrm{i}=1}^{N} N_{I}(x)\left[u_{I}+H(x) \alpha_{I}+\sum_{\alpha=1}^{4} F_{\alpha}(x) \mathrm{b}_{\mathrm{I}}^{\alpha}\right]
$$

Where: $N_{I}(x)$ and $u_{I}$ are the conventional finite element and the node displacement of the shape function; $\alpha_{I}$ and $b_{I}$ are the additional degree of freedom of the fracture surface node and the additional degrees of freedom of the crack tip that embedded. $H(\mathrm{x})$ are the step function that describes the crack surface, see Eq.2, $\mathrm{F}_{\alpha}(\mathrm{x})$ is the asymptotic function that represents the crack tip, see Eq.3.

$$
H(x)=\left\{\begin{array}{cc}
1 & \text { if }\left(x-x^{*}\right) \cdot \mathrm{n} \geq 0 \\
-1 & \text { others }
\end{array}\right.
$$

Where: $x$ is the Gaussian integration point; $x^{*}$ is the distance from the nearest point on the crack surface; $\mathrm{n}$ is the unit outside the normal vector.

$$
F_{\alpha}(x)=\left[\sqrt{r} \sin \frac{\theta}{2}, \sqrt{r} \cos \frac{\theta}{2}, \sqrt{r} \sin \theta \sin \frac{\theta}{2}, \sqrt{r} \sin \theta \cos \frac{\theta}{2}\right]
$$

Where: $(r, \theta)$ It is the polar coordinates of the origin of the crack tip.
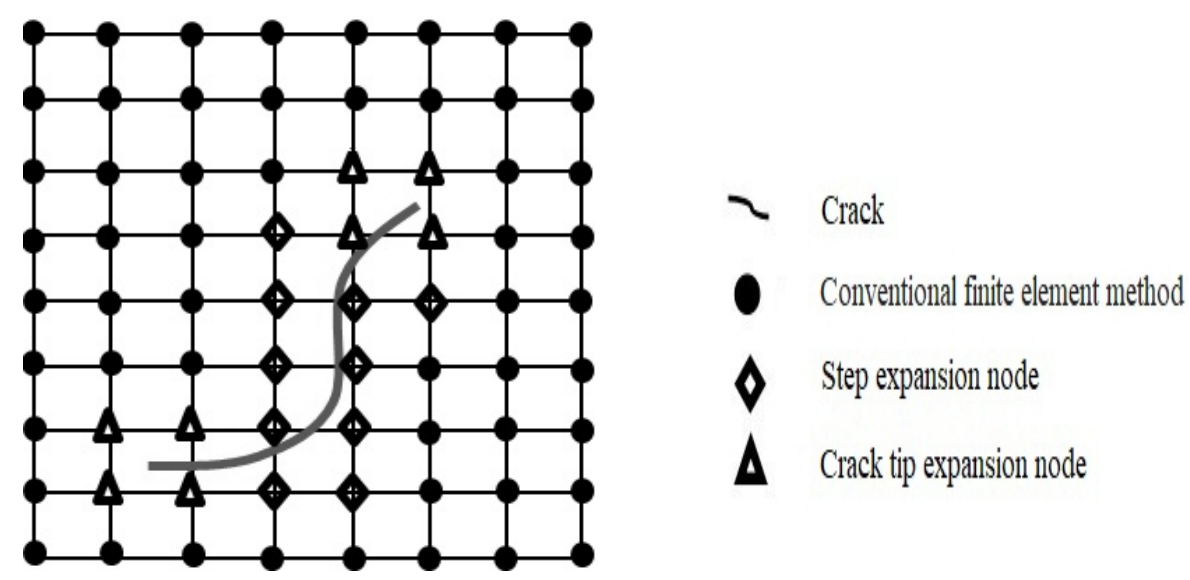

Fig. 1 The unit node extension type

Cracking Criteria. The initial criterion for the formation of fractures is the maximum principal stress criterion (That is, when the maximum principal stress value of the material reaches the set fracture boundary). The expression is as follows:

$$
f=\left\{\frac{\left\langle\sigma_{\max }\right\rangle}{\sigma_{x}^{0}}\right\}
$$


Where: $\sigma_{\max }^{0}$ is the critical maximum principal stress of material damage. \langle\rangle is the Macaulay brackets, which indicates that pure compressive stress does not produce initial damage.

The evolution of the damage adopted linear softening model. The fracture can be the criterion for the separation of the fracture surface. The cracking direction of the fracture is perpendicular to the maximum circumferential tensile stress, and every step of the crack is extended to visually describe the propagation path of the fracture.

\section{Analysis of Bearing Capacity of Pressure Pipeline}

Numerical Calculation Model. A numerical analysis model is established for the model of pressure pipeline model of a hydropower station. The model size is $12.5 \mathrm{~m} \times 12.5 \mathrm{~m} \times 0.6 \mathrm{~m}$.Pipe outside diameter is $4.1 \mathrm{~m}$ and inside diameter is $3.1 \mathrm{~m}$. The steel liner with $16 \mathrm{Mn}$ steel plate thickness is $16 \mathrm{~mm}$. Inner layer of ring steel is $3 \Phi 28$ and middle layer is $3 \Phi 32$ and outer layer is 3Ф36. Pipeline and the dam side of the groove combined parts set the thickness of $15 \mathrm{~mm}$ PS foam cushion. The numerical model takes $1 / 3$ of the model test prototype along the pipe axis. That is $0.2 \mathrm{~m}$ thickness and with a group of reinforcement. The remaining dimensions are unchanged and the mesh is shown in Fig. 2.

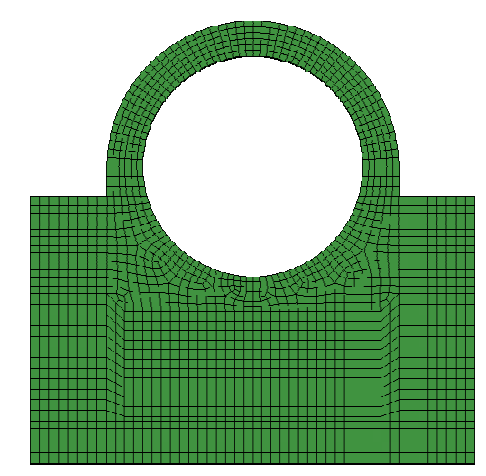

(a) The mesh of dam and pipe

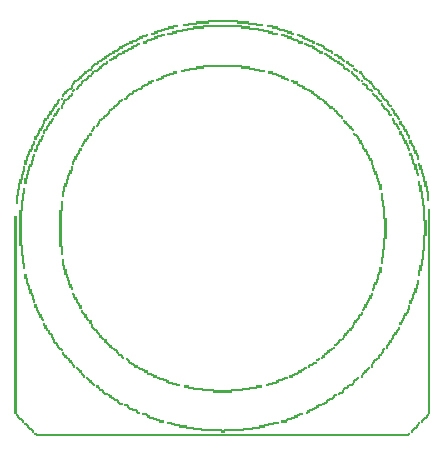

(a) The mesh of reinforcement

Fig.2 Finite element model

The concrete element is an 8-node 6-sided solid element. The steel lining element is a 4-point shell element. The reinforcement element is a 2-point bar element. The numerical calculation model divides 2189 elements o which 1701 concrete elements. Steel lining element is 104 and reinforcement element is 384 . The origin of the coordinates lies in the lower left corner of the dam. The horizontal axis perpendicular to the tube axis is the x-axis and the vertical direction is the $\mathrm{y}$-axis. The dam is made of $\mathrm{C} 15$ concrete and the wrapped concrete is packed with normal C25 concrete. The material parameters are shown in Table 1 . The calculated load is consistent with the model test. The water pressure in the pipeline is $1.21 \mathrm{Mpa}$.In view of the original test model produced by the "supine" in the test site. Therefore, the numerical simulation does not consider the role of structural gravity. 
Table 1 Material mechanics parameters

\begin{tabular}{ccccc}
\hline Material name & Density $\left(\mathrm{kg} / \mathrm{m}^{3}\right)$ & $\begin{array}{c}\text { Elastic Modulus } \\
(\mathrm{MPa})\end{array}$ & Poisson's ratio & $\begin{array}{c}\text { Tensile strength } \\
(\mathrm{MPa})\end{array}$ \\
\hline Pipe concrete & 2500 & $2.80 \times 10^{4}$ & 0.167 & 2.40 \\
Dam concrete & 2400 & $2.20 \times 10^{4}$ & 0.167 & 1.27 \\
Steel line & 7800 & $1.98 \times 10^{5}$ & 0.300 & 350 \\
Reinforcement & 7800 & $2.05 \times 10^{5}$ & 0.300 & 375 \\
Cushion & 200 & 1 & 0.300 & 9.40 \\
\hline
\end{tabular}

Analysis of Crack Propagation Process of Peripheral Concrete. The results of extended finite element analysis show that: When steel-lined reinforced concrete penstocks are subjected to internal water pressure. The concrete of top of penstock inside and penstock waist produce cracks firstly .There are more cracks at the right side of top of penstock inside and penstock waist .The left side of penstock waist produces a single crack. With the increasing of internal water pressure. Cracks which at the top of penstock extend radially from the inside to the outside so as the cracks at the penstock waist. The cracks are folded in the process of expansion through the interior of the element. When the internal water pressure is $0.81 \mathrm{Mpa}$ the first penetrating crack appeared at the left side of penstock waist. As shown in Fig. 3 (a).

When the internal water pressure increases to $1 \mathrm{MPa}$. The number of cracks gradually increased and crack length and width gradually increased. Pipe top and the upper part of the penstock produces a number of penetrating cracks. At the same time inside the bottom of the pipe there is a number of concrete cracks. Due to the damaging effect of the dam temporarily not through the pipeline. As shown in Fig. 3(b). When the internal water pressure increases to $1.21 \mathrm{MPa}$. The number of cracks tends to be stable. Part of the non-penetrating cracks to further develop and through the entire pipeline. The final cracking range is shown in Fig. 3(c). The distribution of cracks is roughly symmetrical.

In addition the results show that $[8,9]$ the initial crack load of concrete is $0.7 \mathrm{MPa}$. Cracks firstly appeared on the left side of the waist and the first crack cracked to wear. In the process of the internal pressure load from $0.7 \mathrm{MPa}$ gradually increased to $1.21 \mathrm{MPa}$. The upper part of the pipe appeared a series of cracked small cracks resulting in a number of through cracks. Its distribution is roughly symmetrical .As shown in Fig. 4.

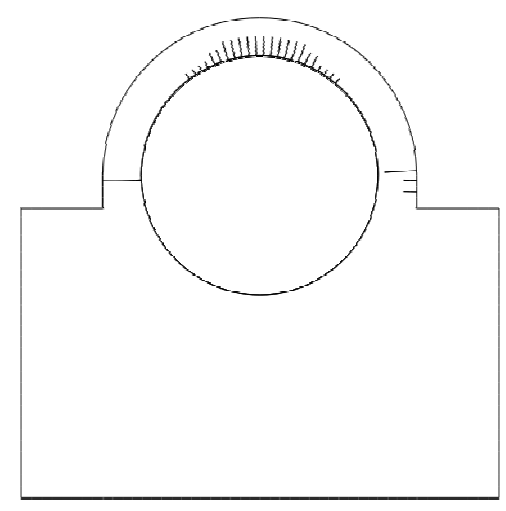

(a) tube-penetrating cracking 

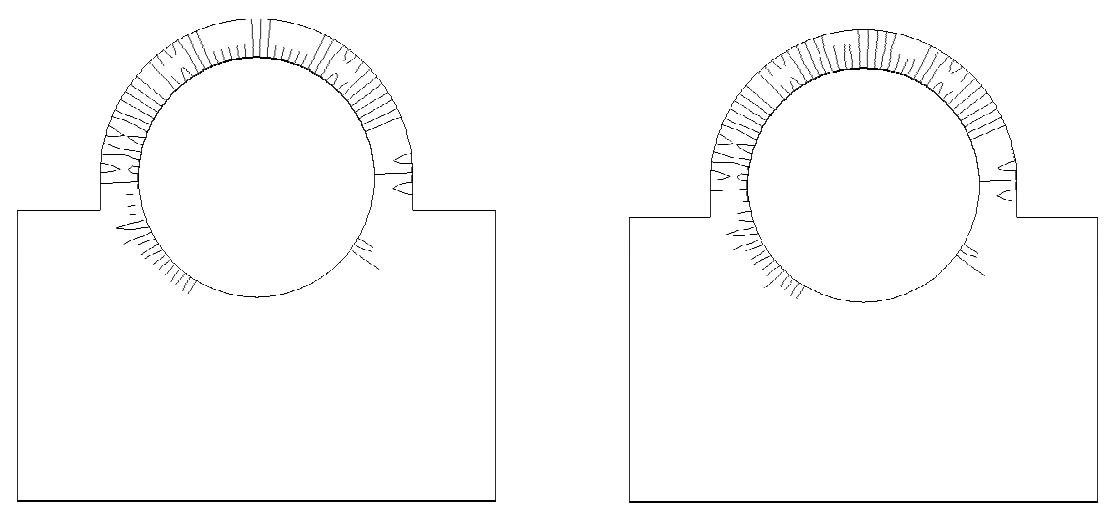

(b) internal pressure of 1.0MPa, pipe cracking area

(c) internal pressure of $1.21 \mathrm{MPa}$, pipe cracking area

Fig.3 Pressure pipe cracking process

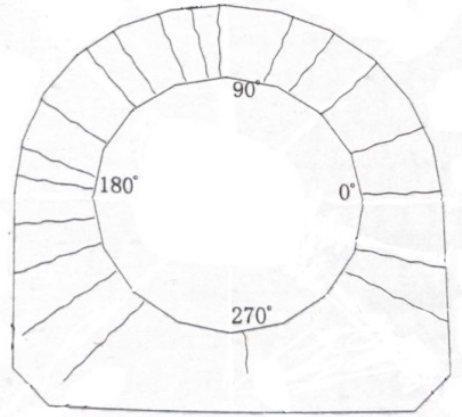

Fig.4 Pressure pipe model test cracking profile

Calculation of Crack Width of Outer Concrete. In the conventional finite element, such as the smeared crack model and the distributed crack model in the simulation of reinforced concrete structure cracking, the cracks dispersed in the unit, can not directly obtain the crack width, generally, the width of the crack is calculated by the finite element analysis of the stress of the reinforcement into the standard crack width formula.. The extended finite element can simulate the expansion of the crack, and can fully reflect the process of the concrete from continuous to discontinuity. According to the results of extended finite element calculation, the crack width of steel-lined reinforced concrete pressure pipe outsourcing concrete is calculated by the distance difference between two nodes before and after cracking. And compared with the crack width value calculated by using hydraulic concrete structure design code [10], this crack width value does not take into account the influence factor of the long term load.

The numerical calculation of the crack width is: the extended finite element method is realized by describing the displacement function when the displacement is discontinuous. As shown in Fig. 5, after the unit B is cracked, the nodes 2,3,6,7 will increase the degree of freedom in each degree of freedom, it becomes the new node $2^{\prime}, 3^{\prime}, 6^{\prime}, 7^{\prime}$.As the cracking of the concrete is similar to the type I cracking (Open Type), when the unit B is cracked through, the sum of the distance difference between nodes 6 and 7 is the crack width. 


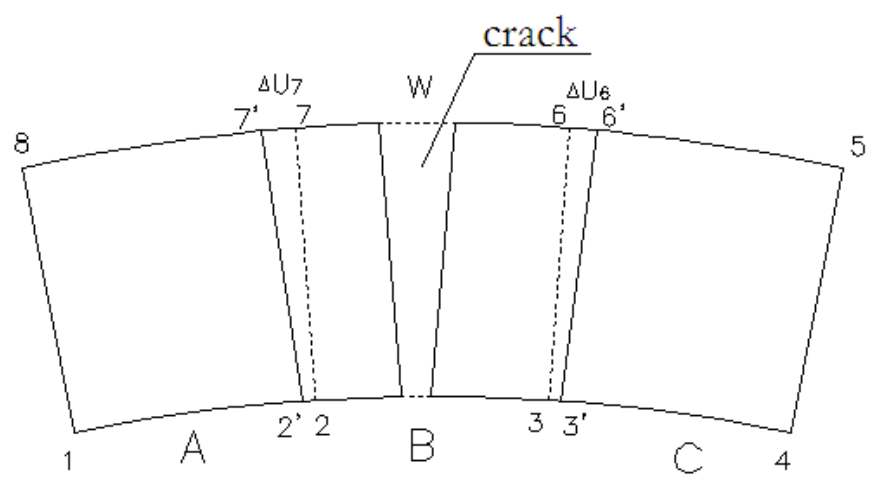

Fig.5 Extended finite element cracking unit

The formula for calculating the crack width of the extended finite element cracking element is:

$\mathrm{W}=\Delta \mathrm{U}_{i}+\Delta \mathrm{U}_{i+1}$

Where: $W$ is the crack width, $i$ is the node number, $\Delta U$ is the node distance difference;

Select the characteristic points of the pressure pipe, calculate the crack width of the outside concrete surface of steel lined reinforced concrete penstocks by numerical calculation method and the crack calculation formula[10], and compared with the measured values of the model test, the results are shown in Table 2.

Table 2 Steel-Lined Reinforced Concrete Penstocks Crack Width (Unit: mm)

\begin{tabular}{c|ccccccc}
\hline Feature Points & $0^{\circ}$ & $22.5^{\circ}$ & $67.5^{\circ}$ & $90^{\circ}$ & $135^{\circ}$ & $165.5^{\circ}$ & $180^{\circ}$ \\
\hline $\begin{array}{c}\text { Numerical Calculated } \\
\text { Value }\end{array}$ & 0.21 & 0.17 & 0.15 & 0.21 & 0.20 & 0.19 & 0.25 \\
$\begin{array}{c}\text { Formula Calculated } \\
\text { Value }\end{array}$ & 0.12 & 0.09 & 0.11 & 0.20 & 0.12 & 0.12 & 014 \\
Measured Value & 0.16 & 0.15 & 0.16 & 0.15 & 0.23 & 0.18 & 0.18 \\
\hline
\end{tabular}

From the table we can see, the pressure pipe maximum crack width of the numerical calculated value, the formula calculated values were $0.25 \mathrm{~mm}$ and $0.20 \mathrm{~mm}$, are less than the design allowable value of $0.3 \mathrm{~mm}$, the numerical calculated value of the crack width is closer to the measured value.

Stress Analysis of Steel in Pressure Pipe. Under the design internal water pressure load, the extended finite element method calculation results show that the maximum steel liner stress is at the top of pipe, the calculated value is $73.8 \mathrm{MPa}$. The maximum stress of the reinforcement occurs at the top and the right of the inner reinforcement pipe, the calculated value is $38.4 \mathrm{MPa}$. The stress distribution of steel is approximately symmetrical. The stress of steel lining and inner reinforced at the top of the pipe is greater than the waist. The stress of middle and outer reinforcement at waist is greater than the top of the pipe. The stress of reinforcement in the upper half is greater than that in the lower half, lowest stress is at the bottom of pipe. In addition, the stress distribution of steel is not only related to the location of the structure, but also related to the form of structural cracks, the stress at the crack is greater than the stress at the crack free.

Comparing with the stress values in the extended finite element and the model test results show that at the waist of pipe, the maximum stress calculation and experimental value of reinforcement 
are $30.5 \mathrm{MPa}$ and $43.3 \mathrm{MPa}$ respectively. At the top of pipe, the maximum stress value of steel liner is $73.8 \mathrm{Mpa}, 23.8 \%$ of the yield strength. The maximum stress value of model test is $88.9 \mathrm{MPa}$, $28.7 \%$ of the yield strength. On the whole, the stress value of the steel at top-waist section of the penstock is similar to that of the model test. The stress distribution of the steel calculated by numerical method is basically consistent with the model test.

\section{Conclusion}

Based on the continuous-discontinuous method, the cracking of steel-lined reinforced concrete pressure pipe is studied, and the results of the concrete test of large-scale steel-lined reinforced concrete pipe are compared and analyzed. The main conclusions are as follows:

1. Compared with the model test, it is shown that the extended finite element method is used to calculate the germination process, the initial crack load and the crack number of the concrete pipe are close to the model test results.

2. Based on the extended finite element method, the numerical calculation method of the crack width of the pressure pipe is given. The calculated value of the maximum crack width is $0.25 \mathrm{~mm}$ and $0.23 \mathrm{~mm}$ respectively, which are less than the design allowable value of $0.3 \mathrm{~mm}$. The calculated value of the crack width is closer to the measured value of the model test.

3. The stress distribution of the steel pipe and the steel bar calculated by the extended finite element method is in good agreement with the model test, which can better reflect the bearing law of the steel lining reinforced concrete pressure pipe.

4. Extended finite element method, can better simulate the concrete structure cracking and crack propagation of the whole process, this is, the structure is from continuous to non-continuous process, and has certain computational precision, which has better application prospect in the numerical simulation of reinforced concrete pipe.

\section{Acknowledgements}

This work was financially supported by the National Natural Science Foundation of China(No. 51379107)

\section{References}

[1]Jinzhu Fu.Study on the structure of penstock structureon downstream dam surface and cracks of encased concrete of hydropower station(China Water Conserpancy and Hydropower Publishing House, Beijing 2007)

[2]Guozhi Gong, wei Zhang,Hegao Wu. Study on crack control of concrete wall of steel lined reinforced concrete penstocks.Rock and Soil Mechanics, Vol.28,No.1,p.51-56,2007(In Chinese)

[3]Zienkiewicz O C, Taylor R L,Zhu J Z. The Finite Element Method.(Sixth edition.Butterworth-Heinemann, 2006)

[4]Cundall P A. A computer model for simulating progressive large scale movement in block rock system Proceedings of the International Symposium Rock Fracture ISRM. p.1-8,1971

[5] Yongjia Wang,Jibo Xing.Discrete element method and its application in rock and soil mechanics[M].Shenyang:Northeast Institute of Technology Press, 1991(In Chinese)

[6] Sherong Zhang, Gaohui Wang, Bo Sun.Seismic potential failure mode analysis of concrete gravity dam based on extended finite element method.Journal of hydraulic engineering.Vol.43,No.12,p.1431-1439,2012 (In Chinese)

[7] Xiujun Fang, Feng Jin, Jinting WANG.Cohesive crack model based on extended finite element 
method.Journal of Tsinghua University.Vol.47,No.3,p.344-347,2007(In Chinese)

[8] University of Hydraulic and Electric Engineering. Large scale plane structure model test research on steel lined reinforced concrete penstock in Three Gorges Hydropower station (Hydropower Engineering Institute of Gezhouba, Yichang 1996)

[9] Yao Yang, Hanming Wu, Xuetang Yang, Yishu Fu. Experimental Reseach on Cracking Characteristics of Pentocks for the Three Gorges Power Station. Journal of University of Hydraulic And Electric Engineering, Yichang, Vol. 20 ,No.3, p. 47-50,1998 (in Chinese)

[10] SL191-2008,Design code for hydraulic concrete structures.Beijing: China Water Conservancy and Hydropower Publishing House, 2009 